\title{
The Investigation and Analysis of Making Use of Private Vehicle Conduct Immediate Physical Distribution
}

\author{
Su Hong*, Ying Miaojing, Jiang Leping, Zhang Xinjia, Li Congjia
}

Electromechanical Engineering Academy, Jiaxing University, Jiaxing, China

\section{Email address:}

1520153742@qq.com (Su Hong)

*Corresponding author

\section{To cite this article:}

Su Hong, Ying Miaojing, Jiang Leping, Zhang Xinjia, Li Congjia. The Investigation and Analysis of Making Use of Private Vehicle Conduct Immediate Physical Distribution. Science Discovery. Vol. 4, No. 5, 2016, pp. 280-284. doi: 10.11648/j.sd.20160405.13

Received: August 1, 2016; Accepted: September 6, 2016; Published: September 28, 2016

\begin{abstract}
With the improvement of people's living standards, private cars have been gradually popularized, but meanwhile they also add pressure on urban transportation. To alleviate traffic congestion, improve the efficiency of utilization of private cars and facilitate the public to send or receive items, the idea of realtime logistics was proposed in this paper. Through the methods of questionnaire and interviews, this paper investigates into the degree of public acceptance, the reason and the psychological price of public on the use of private cars to carry out the realtime logistics. Finally it is concluded that in certain conditions immediate physical distribution can be used.
\end{abstract}

Keywords: Private Car, Immediate Physical Distribution, Investigation and Analysis

\section{利用私家车辆进行即时物流的调查与分析}

苏红 ${ }^{*}$ 应妙静, 姜乐萍, 张金佳, 李联佳

机电工程学院, 嘉兴学院, 嘉兴, 中国

邮箱

1520153742@qq. com（苏红）

摘要：随着人民生活水平的提高, 私家车已逐步普及, 却也增加城市交通压力。为缓解交通拥堵, 提高私家车的利用 率, 同时方便市民收寄物品, 本文就市民和私家车车主对利用私家车进行即时物流的接受程度、原因、心理价位等方 面通过问卷、访谈等方式进行了调查, 最后得出在一定条件可利用私家车进行即时物。

关键词: 私家车, 即时物流, 调查与分析

\section{1. 引言}

目前, 中国市场经济的高速发展对城市物流提出新的 高要求挑战。以市场经济充分发展为特征的现代社会化生 产的发展反映在物流领域, 表现为商品的大进大出和快进 快出。然而, 在我国, 由于长期重生产轻流通, 在流通中
又重商流轻物流, 使我国物流尤其是城市物流存在着明显 的不协调状况 [1]。

其次我国经济的快速发展，人民生活水平的提高，拥 有私家车的市民越来越多。一般情况下, 私家车在行驶时 后备箱都处于一种闲置状态, 这就造成了一种资源的浪费。 此时如果顺应互联网热潮, 使私家车、互联网、即时物流 有机结合则成了一个新机遇。即通过互联网（例如设计一 款APP）使得私家车 “顺风化”, 让物品顺风搭乘私家车, 
花费较低的价格运输物品。本文为了解这个项目计划的可 行性, 对嘉兴市市民与私家车车主进行了调查 [2]。

\section{2. 调查相关情况}

\section{1. 调查方法}

本次调查主要采用了问卷调查法与定点拦截式访问 法相结合的形式 [3]。

\section{2. 样本选取条件}

1) 调查类型及数量: 采用访问的形式调查嘉兴 (中国) 市民500位、私家车主（嘉兴）200位，采用网上问 卷调查的方式调查市民（中国各个城市）5000位、 私家车主（中国各个城市）1000位。

2) 年龄范围: 15-60岁。

3) 关于问卷调查有效回答: 市民有效回答 4780 个, 有 效率为 $95.6 \%$, 私家车车主有效回答 925 个, 有效率 为 $92.5 \%$ 。

\section{3. 最后统计样本情况}

市民5280位, 私家车主1125位 (私家车主中有已注册 各种打车软件的兼职或全职司机, 也有普通的私家车车主, 调查对象的范围具有代表性）。

\section{4 . 问题及处理}

问卷与访问中涉及到与课题相关的 6 个方面问题, 对 调查结果我们用SPSS统计软件进行数据分析, 然后根据本 次研究的主题进行具体的解读, 本文数据均来自于此次调 查 $[4]$ 。

\section{3. 问卷数据统计结果及分析}

\section{1 . 对市民的调查}

调查数据

表1 嘉兴市市民调查结果表。

\begin{tabular}{|c|c|c|c|c|c|}
\hline \multirow{2}{*}{ 性别 } & 男 & $42.5 \%$ & \multirow{2}{*}{ 寄物范围 } & 市内 & $48.0 \%$ \\
\hline & 女 & $57.5 \%$ & & 省内 & $52.0 \%$ \\
\hline \multirow{4}{*}{ 年龄（岁） } & $15-25$ & $32.8 \%$ & \multirow{4}{*}{ 是否接受私家车即时物流的寄物方式 } & & \\
\hline & $26-35$ & $24.3 \%$ & & 接受 & $62.3 \%$ \\
\hline & $36-45$ & $22.2 \%$ & & & \\
\hline & $46-60$ & $20.7 \%$ & & 不接受 & $37.7 \%$ \\
\hline \multirow{3}{*}{ 职业 } & 学生 & $31.5 \%$ & \multirow{4}{*}{ 不接受原因 } & 安全问题 & $62.0 \%$ \\
\hline & 上班族 & $53.5 \%$ & & 运输速度问题 & $29.3 \%$ \\
\hline & 普通居民 & $15.0 \%$ & & 物件不重要没有必要 & 5. $3 \%$ \\
\hline \multirow{4}{*}{ 寄物频率 } & 一周多次 & $15.0 \%$ & & 寄物次数少没有必要 & $3.4 \%$ \\
\hline & 一周一次 & $28.0 \%$ & \multirow{3}{*}{ 可接受的价格 } & 比普通快递费低 & $58.8 \%$ \\
\hline & 一月一次 & $23.8 \%$ & & 与普通快递费一样 & $27.6 \%$ \\
\hline & 很少 & $25.6 \%$ & & 比普通快递高 & $13.6 \%$ \\
\hline
\end{tabular}

市民的调查结果如下:

在所调查的 5280 名市民中有 $62.3 \%$ 的人表示可以接受 并愿意尝试用私家车进行即时物流这种运输方式, 在这 $62.3 \%$ 的市民当中有 $58.8 \%$ 的人希望价格可以比普通快递 低, 有 $27.6 \%$ 的人希望价格可以和普通快递价格一致，有 13. $6 \%$ 的人表示运送贵重物品时价格比普通快递高也可以 接受; 另外 $37.7 \%$ 的人表示不愿意尝试私家车即时物流, 其中 $62 \%$ 的人是因为担心在安全方面得不到保障，29.3\% 的人担心这种方式并不能很好的发挥即时运货的作用, $5.3 \%$ 的人表示寄送的物件并不重要也不需要立刻到达目 的地, 觉得没必要采用该方式, 最后 $3.4 \%$ 的人表示寄送物 件的次数太少也不需要这种方式。

\section{具体分析}

从整体上看, 在所调查的人当中, 只有 $33.2 \%$ 的人平 时很少或不寄物品, 有 $62.3 \%$ 的人表示可以接受并尝试该 项目, 不接受人群最关注安全问题, 其次是运输速度。因 此, 要想利用私家车进行即时物流, 安全是首要问题。为 保障市民物品的安全, 可对注册的私家车司机进行实名认 证, 签署安全保护协议。
从年龄段来看，如表 2 所示，蓝色的为此年龄段总人 数, 橙色的为该年龄段接受并愿意尝试此项目的人数。

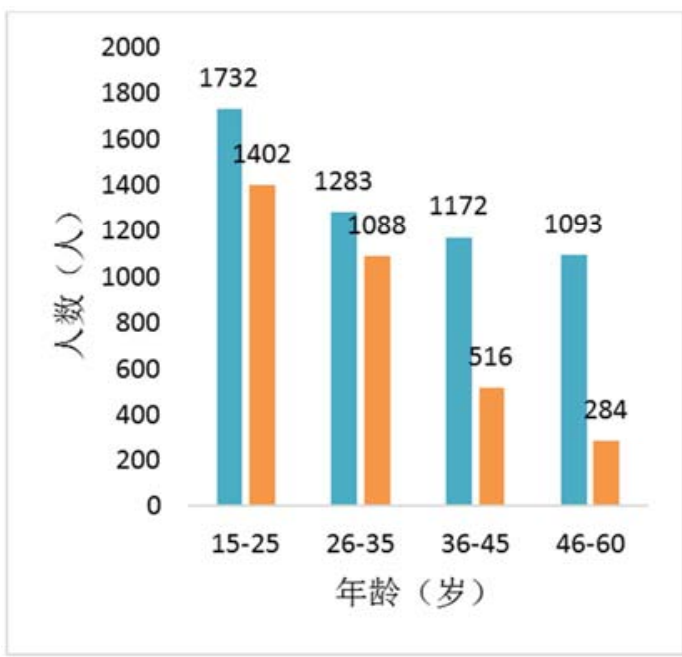

图1 人数随年龄分布表。 
通过对比可以看出：26-35岁，36-45岁，46-60岁这 三个年龄段的调查人数差距不大, 相比之下, $15-25$ 这个 年龄段的人数要多。这四个年龄段的接受率分别为: $81 \%$ 、 $85 \% 、 44 \% 、 26 \%$ 。可见，从接受率方面来看 15-35岁之间的 人更愿意尝试这一项目, 而46-60岁之间的人的接受率是 最低的, 而接受率随着年龄的增长呈现下降的趋势。

经过分析, 产生这一现象的主要原因是: 利用私家车 进行即时物流必然会与互联网相结合。15-25岁之间的人 大多是学生 (高中生和大学生), 对互联网比较熟悉, 相 比已经步入社会开始工作的人来说，他们有更多的时间和 精力来接触互联网, 而我们的调查主要是基于网上问卷, 因此在被调查者中, 这一年龄段的人数明显高于其他年龄 段; 再者这一年龄段的人更敢于去尝试新鲜事物; 并且这 个年龄段的学生经济来源主要是父母, 对金钱意识比较淡 薄, 所以他们对于运货的价格方面稍微高一点也普遍能接 受。而位于 $26-35$ 岁和 $36-45$ 岁这两个年龄段的人大多是上 班族, 较前者有更多的社会经验, 在互联网的认识和使用 频率上可能不如前者, 但是他们对寄物的需求却是最多的, 调查结果也显示 26-35岁这个年龄人是所有年龄段中寄物 品频率最高的一个年龄段; 正因为他们有独立的工作, 消 费能力相对另外两组参照对象是较高的, 且对时间的珍惜 程度也是相对最高的, 那么假设该项目投入运行已接近稳 定状态, 该年龄段将会成为最大的消费群体。45-60岁这
个年龄段的人思想上较年轻人相对保守一点, 对于互联网 的认识比较模糊, 并且他们寄物品的频率也是最低的, 这 也就使得这个年龄段的人接受率最低成为必然。但是随着 经济的发展, 互联网的渗透力逐渐增强。调查研究表明, “我国老年群体接触互联网的比例不断上升, 老年网民引 起绝对的数量、增长的速度、发展的潜力成为网络媒体不 可忽视的受众群众”。45-60这一年龄段甚至年龄更高的 人都将会成为该项目的潜在客户 [5]。

从人们所能接受的价格来看, 一半以上的人都希望价 格能比普通物流的价格低; 接近三分之一的表示与普通物 流价格一致便可以; 少部分人表示, 如果是贵重物品的话 价格高一点也是可以接受的。利用私家车进行即时物流实 际上是让物品搭乘顺风车, 并不是让司机去专门运输货物, 因此在对资源的充分利用以及交通可持续发展分析的一 个理论上是可以满足市民对价格的需求的 [6]。

综上所述，该项目在市民意见方面的接受度还可以， 如果项目得以实施, 普识度得到提高, 预计接受人数将会 增加, 有很大的发展前景。

\section{2. 对私家车车主的调查}

\section{调查数据}

表2 私家车车主调查结果表。

\begin{tabular}{lll}
\hline 司机类型 & 打车软件用户 & $43.3 \%$ \\
& 普通私家车车主 & $56.7 \%$ \\
是否接受私家车即时物流的寄物方式 & 接受 & $64.3 \%$ \\
& 不接受 & $35.7 \%$ \\
& 安全问题 & $46.8 \%$ \\
& 不熟悉此项业务 & $32.1 \%$ \\
不接受的原因 & 没时间 & $12.3 \%$ \\
& 不差钱 & $8.8 \%$ \\
& 空余 & $82.0 \%$ \\
后备箱 & 不空余 & $18.0 \%$ \\
& 比载人价格低 & $31.2 \%$ \\
可接受的价格 (打车软件用户) & 与载人价格一致 & $35.7 \%$ \\
& 比载人价格高 & $33.1 \%$ \\
& 比普通快递低 & $46.2 \%$ \\
可接受的价格 (普通私家车车主) & 与普通快递一致 & $29.8 \%$ \\
& 比普通快递高 & $24.0 \%$ \\
\hline
\end{tabular}

私家车车主的调查结果如下:

所有调查的 1125 名私家车车主中, 有 $64.3 \%$ 的人表示 可以接受并尝试即时物流, 其余 $35.7 \%$ 的人表示不愿意接 受。不接受的人群中 $46.8 \%$ 的人考虑到安全问题， $32.1 \%$ 的人表示对此项业务不熟悉不愿冒险，12.3\%的人是因为 没时间进行此项服务, $8.8 \%$ 的人的原因是自身经济方面不 差这些钱。在愿意接受的车主中, 对于打车软件用户的司 机而言, 愿意接受的价格比载人高、与载人一致、比载人 低各占约三分之一; 对于普通私家车主而言, 接近一般的 人表示可以接受比普通快递低的价格, 约四分之一的人可 以接受的价格与普通快递价格一致, 剩余不到四分之一的 表示比普通快递价格高才能接受。
基本分析

从整体上看, 所有调查车主中有 $82 \%$ 的后备箱经常处 于闲置状态。其中有 $64.3 \%$ 的人表示可以接受并尝试进行 即时物流, 其他不愿尝试的车主中 $46.8 \%$ 是因为对物品的 安全性有顾虑, 这也是此项目必须要解决的一个问题。所 以在项目的规划中必须考虑让寄物市民也进行实名认证 的注册的环节, 从源头上对物品的来源进行了有效的控制, 对车主的安全方面也是一大保障。另有 $32.1 \%$ 的人表示目 前对此项业务不熟悉, 如果项目投入运行并接近稳定状态 时, 此项目对于普通大众不再陌生时, 相信因对此业务不 熟悉而不愿意接受的车主中的很大一部分都愿意跟随潮 流进行即时物流的尝试。 
从价格方面来看, 已注册打车软件车主所需要的费用 会与目前载人收入进行比较考虑的。这是因为他们已成为 职业或半职业司机, 每天随载人时间、地点的不确定性而 无法确认自己的行车路线, 这可能会导致物品顺风搭乘这 些车的低概率发生, 因此这些车主所希望的价格会高。普 通车主由于平时并不依靠车载人的收入, 所以对于顺路可 以赚取运输外快的事情表示很愿意, 他们也觉得运输物品 比起载人在地点上更具常规性与稳定性, 因此在这些普通 车主中, 有 $42.6 \%$ 的人可以接受比普通快递更低的价格, $29.8 \%$ 的人想要与普通快递一致的价格, 只有 $24 \%$ 的人表示 可希望价格要比普通快递高。

综上所述, 利用私家车进行即时物流在私家车司机方 面虽目前有阻力, 但还是可以有不错的发展前景的。

\section{4. 综合分析}

\section{1. 实施该项目需解决的问题与实施方案}

通过上述分析可知, 目前条件下, 利用私家车进行即 时物流最大的两个阻力是安全和价格。除此之外, 物品路 线的合理规划以及站点的设置也是非常重要的。因此为使 该项目的可行性提升以及确保后续的一系列实施的顺利 进行, 必须解决以下问题:

首先, 我们要解决的是实现方式。随着社会的发展, 互联网已经成为这个时代的主旋律, 将互联网与物流结合 在一起便产生了 “物联网” [7]。虽然物联网已经在国内 物流业实现了一些应用比如滴滴打车、优步等利用私家车 资源的探索取得了明显的成绩，但它仍然是一个可以持续 发展的事物, 但已足够给我们以启发 [8]。就目前而言, 互 联网已深入到普通人们的生活中, 用手机上网已经是一种 非常便利且随处可见的方式 [9]。我国总的网民数量6.49 亿, 手机网民数量达 5.57 亿。（数据来源：中国互联网络 信息中心) 因此, 我们通过互联网将市民与车主联系起来 是切实可行的。我们可以设计一个网站或一个手机客户端 来专门运行该业务。

其次, 我们要解决安全问题。市民担心自己的物品在 运输过程中遗失或者是对私家车车主的身份表示怀疑, 而 私家车车主又担心运输的物品来源是否安全, 有无违禁物 品等。我们是通过互联网的方式来进行联系, 为保证各方 的安全, 用户在注册时都必须进行实名认证, 并且我国现 在的技术水平也支持实名认证 $[10]$ 。

再者, 我们要解决价格问题。通过调查分析我们发现, 车主与市民的心理价位或多或少有些差距, 如果每一单市 民或车主所给出的价格都是不变的话会大大降低接单的 成功率。因此每一单旁边都可以设置价格沟通栏, 可以让 双方进行沟通直至二者达成一致或放弃此单。

最后是路线的规划和站点的选择问题。首先应对目标 城市的交通路线有一个整体的概念，对每条路上每天通过 的私家车的数量进行统计, 然后与居民的聚集程度结合起 来选择合适的站点 (这一点的完成还需要后续进行大量的 调查与分析）。在一定规模后便可以形成市与市之间的交 通网络。
整体运行方案: 首先设计一款产品（网站或手机APP 等) 为该项目服务。司机与私家车主通过实名认证的方式 进行注册, 然后便可以发布或接受订单, 对于价格的问题 已经在上述中进行解决。市民将自己的物品投递到站点内, 该站点的特点通过刷身份证的方式进行投递，即站点的投 递箱分为大小不同的格子, 市民选择适合自己物品的格子 后刷身份证格子打开, 将物品放入后市民可得到一个验证 码, 输入验证码便可以打开相应的方格取出物品, 物主可 在接单成功后告知私家车主验证码以便取物。

\section{2. 实施该项目的优点}

1) 采用私家车运输货物, 取代了一定数量的市内货车, 有助于减轻诱发交通对城市交通道路空间需求带 来的压力, 在一定程度上缓解了交通拥堵。

2) 可以很好将私家车的后备箱利用起来, 提高了私家 车利用率的情况下也给车主带来了一些额外的收 入。

3）使市民在寄物方面有了更多的选择性, 给市民带来 方便。

4) 利用私家车进行即时物流采用互联网平台, 使私家 车不再局限于载人使用、使货物不再局限于物流公 司, 突破了物流集体化运输的局限, 创造性地解决 了车辆交易问题, 极大地加快了私家车共乘的步伐。

5) 私家车载物化对改善城市环境, 降低碳排放的作用 也显现出来。

\section{3. 该项目实施后可能存在的漏洞}

1）采用实名认证之后市民的信息可能会泄露, 因此, 信息安全将会是大家关注的一个重点。

2) 车主时间地点的随机性使得货物与私家车路线的 匹配存在一定的困难。

\section{5. 结论}

本研究表明, 无论是市民还是私家车主方面, 想要推 行该项目都有一定的阻力, 其中最大的一个问题就是安全 问题, 其次就是价格问题, 本文就这两个问题给出了自己 的解决方案。但是, 综合而言从市民和私家车车主两方面 出发, 利用私家车进行即时物流都是有很大的发展前景的。 致谢

本文为嘉兴学院SRT重点项目《利用私家车辆进行即 时物流的探索与研究》的阶段性成果之一。

\section{参考文献}

[1]王静。浅析我国市内物流配送发展 [J]。科技信 息, 2013(14).

[2] 龚桂雄, 柳超. 私家车 “顺风化” 问题初探 [J]. 交通企业管 理, 2016 (02) : 18-20. 
[3] 蒋听. 公众参与问卷调查方法探讨 [J]. 广州环境科 学, 2008, 23(02) : 36-39.

[4] 史春薇, 田强, 葛寒, 鲁传涛. 基于SPSS统计软件在多元线性 回归校验数据中的应用 [J], 当代化工, 2014, 43 (06).

[5] 季尚尚. 北京地区老年网民网络媒体接触研究 [J]. 新媒体 专题, 2009. 3:76-90.

[6] 疏祥林, 杨柳青. 城市交通可持续发展研究 [J]. 安庆师范学 院学报 (社会科学版), 2006, 25(02): 76-79.
[7] 朱洪波, 杨龙祥, 朱琦. 物联网技术进展与应用 [J]. 南京邮 电大学学报 (自然科学版), 2011, 31 (01) : 1-9.

[8] 周晋, 万婷. 以哈尔滨为例谈顺风车的推行现状与制度化措 施 [J]. 山西建筑, 2014, 40 (24) :262-264.

[9] 王伟. 浅析 web2.0 的应用与发展趋势 [J]. 2008 (6) : 118-119.

[10] 马丁, 李丹. 网络 “实名认证, 网名上网” 技术研究 $[J]$. 通 信技术, 2014. 47.01:91-96. 